\title{
Research on the heat transfer law of gas-liquid two-phase flow in a deepwater wellbore
}

\author{
B. J. Sun, Y. H. Gao, Y. Q. Ma, Z. Y. Wang \& H. Li \\ College of Petroleum Engineering, China University of Petroleum \\ (Huadong), China
}

\begin{abstract}
According to the features of low temperature and Type III boundary conditions during deepwater oil and gas exploitation, an experimental system was designed and built to simulate the heat transfer of deepwater oil and gas. A large number of laboratory experiments were carried out and the relational expressions of the heat transfer as well as the influence of the gas-liquid discharge on the heat transfer of each gas-liquid two-phase flow patterns under the deepwater and lowtemperature Type III boundary conditions were obtained. The results show that the expression in the laminar flow obtained in this paper is largely different from the relational expression of the heat transfer at ordinary temperatures under the simple boundary conditions. The two expressions are in substantial agreement in the turbulent flow. The liquid discharge is the principal factor which influences the heat transfer in the bubbly flow, slug flow and annular flow while the gasliquid two-phase flow has little influence on the heat transfer in the churn flow. Keywords: deepwater, gas-liquid two-phase flow, transfer, experiment.
\end{abstract}

\section{Introduction}

In process of the deepwater oil development, the low-temperature characteristic $\left(2-6^{\circ} \mathrm{C}\right)$ of the seawater can bring about low temperature in a portion of the wellbore. In addition, if it is gas-liquid two-phase flow in the wellbore, the temperature field will be more complex. According to the published documents, the temperature range of current experimental research of the non-boiling cooling heat transfer of the gas-liquid two-phase flow is generally at ordinary temperatures (above $20^{\circ} \mathrm{C}$ ) (e.g. Taitel and Barnea [1]) or low temperature (80K$85 \mathrm{~K}$ with the medium of liquid nitrogen) $[2,3]$. There is no experimental 
research result reported for the circumstances of deepwater and low temperature $\left(0-6^{\circ} \mathrm{C}\right)$. However, the characteristic of liquid within this temperature range is largely different from that of the normal temperature. It has some unique parameter. In this paper, the heat transfer laws of the fluid in the pipe in cold circumstance and the heat transfer laws of the gas-liquid two-phase flow in the pipe are studied. It lays the foundation for the design of the technological parameters of the offshore deepwater oil and gas exploitation.

\section{Experimental system}

\subsection{Experiment equipment and process}

Fig. 1 shows the sketch of equipment and operation flow diagram of the imitating system that simulates the cooling heat transfer of the gas-liquid twophase flow in the deepwater wellbore. The main wellbore consists of two parts, the inner tube for the hot fluid and the annulus for the cold fluid. The sizes are as follows: length $\times$ outer diameter of inner tube $\times$ outer diameter of outer tube $\times$ outer diameter of insulating sheath $=12000 \times 60 \times 100 \times 200 \mathrm{~mm}$; outer diameter of annulus: $\Phi 108 \times 5 \mathrm{~mm}$, inner diameter of annulus: $\Phi 60 \times 5 \mathrm{~mm}$. The working temperature is between $5-65^{\circ} \mathrm{C}$. Wherein, the inner tube refers to the pipe such as a riser or a drill rod contacting with the seawater. The fluid in the annulus between the inner tube and the outer tube imitates the deepwater circumstance. In the experiment, the hot liquid $\left(20-65^{\circ} \mathrm{C}\right)$ is injected from the bottom of the inner tube. The hot liquid can be gas-liquid two-phase flow that has been fully mixed before entering the heat transfer section. The cold liquid is injected

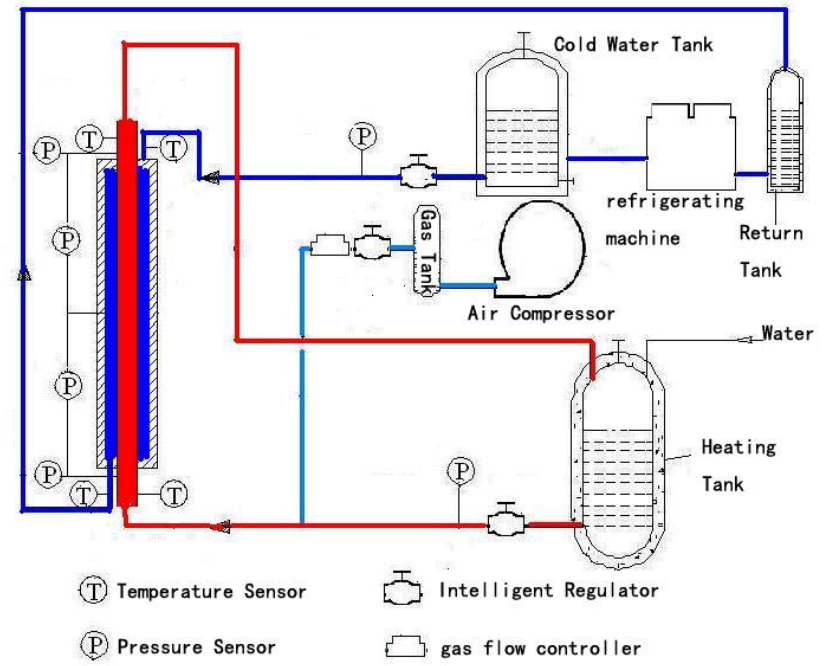

Figure 1: Experiment equipment. 
from the top of the annulus with adjustable flow. Thus a simulating process of the cryogenic cooling heat transfer of the wellbore flow in the deepwater circumstance forms.

The return tank is equipped with an insulating sheath and an electrically heated temperature control system to heat the water in the return tank and carry out the thermostatic control. The temperature is controllable between the ordinary temperatures to $60^{\circ} \mathrm{C}$ with control precision of $\pm 0.5 \%$. The maximum flow is $12 \mathrm{~m}^{3} / \mathrm{h}$ with control precision of $1 \%$.

The cold water is provided by the chiller. The cold water at different temperatures is obtained by adjusting the thermostat of the chiller. The compressor shuts down when the temperature reaches the set value. The temperature is controllable between $2^{\circ} \mathrm{C}$ to $6^{\circ} \mathrm{C}$ with precision of $\pm 0.5^{\circ} \mathrm{C}$. The maximum flow is $10 \mathrm{~m}^{3} / \mathrm{h}$ with control precision of $1 \%$.

The injected air is generated by the compressor, buffered in the gas tank and dried in the condenser. The injected gas discharge is adjusted automatically in the gas discharge control system to keep constant. Injected gas discharge: controllable input between $1-8 \mathrm{Nm}^{3} / \mathrm{min}$ with flow measurement accuracy of $1 \%$

To reduce energy loss, the return tank, the refrigerating tank, and the experiment pipes are all packed in heat shield and thus the complete experiment measurement system can be regarded as an isolated process, which accords with the energy conservation law. In addition, the data in this experiment is collected when the flow and heat transfer become stable.

\subsection{Experimental data acquisition and processing}

\subsubsection{Data acquisition of differential pressure}

As it is multiphase flow in the inner tube and it is sealed within the annular space in the system, the flow pattern is hard to identify through the fluctuation of void fraction. So the method of differential pressure fluctuation is adopted for the identification of this flow pattern. The PCI2013 data acquisition card driver is adopted in the data acquisition system. The set ratings of the basic parameters are as follows: The acquisition frequency is $5 \mathrm{kHz}$ and the resolving power is 12 bit; 2 analog input channels are provided.

The principles of the hardware structure of the data acquisition system are shown in Fig. 2. The differential pressure parameters are converted into standard current signals of $4 \sim 20 \mathrm{~mA}$ by the sensor. Then the multi-channel signal converter converts the different kinds of current signals that the sensors output into voltage signals. Then the voltage signals are sent to the $16 \mathrm{~A} / \mathrm{D}$ converters. The A/D Converter converts the input analog voltage into binary digital signals, which are sent to the computer through the data bus of the computer. The data acquisition and processing software of the differential pressure fluctuation is built with Lab VIEW. The data is output to the file and the analytical processing of it is carried out by the software. 


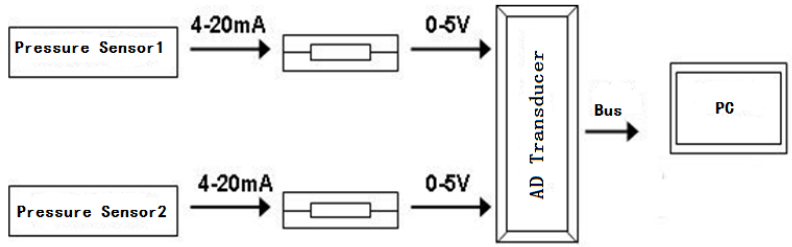

Figure 2: Schematic diagram of the differential pressure acquisition system.

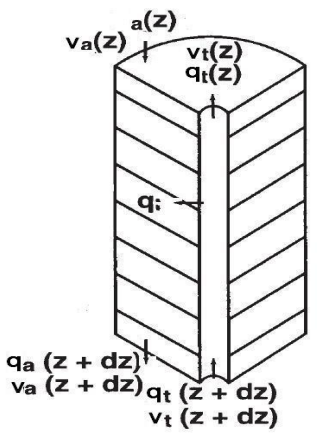

Figure 3: $\quad$ Heat transfer model of experimental equipment.

\subsubsection{Experimental data processing}

The heat transfer model is built based on the experimental pipes, as shown in Fig. 3. Then the energy equation of vertical annulus (e.g. Gao et al. [5]). is obtained:

$$
H_{a}(z+d z)-H_{a}(z)+\frac{1}{2} w_{a} v_{a}^{2}(z+d z)-\frac{1}{2} w_{a} v_{a}^{2}(z)+q_{i}=0
$$

Derived equation:

$$
\frac{d H_{a}}{d z}+w_{a} \cdot \frac{v_{a} d v_{a}}{d z}+\frac{d q_{i}}{d z}=0
$$

$H_{a}(z+d z)$ is the enthalpy of the fluid that enters the element in unit time, $\mathrm{J} / \mathrm{s}$; $H_{a}(z)$ is the enthalpy of the fluid that outflows the element in unit time, $\mathrm{J} / \mathrm{s}$;

$q_{i}$ is the energy that is transferred from the inside of the tube to the element of the annulus in unit time, $\mathrm{J} / \mathrm{s}$;

$v_{a}$ is the speed of the fluid, $\mathrm{m} / \mathrm{s} ; w_{a}$ is the mass flow of the fluid in the annulus, $\mathrm{kg} / \mathrm{s}$;

The energy that is transferred from the inner tube to the element of the annulus in unit time:

$$
q_{t a}=\frac{w_{a} C_{a}}{B}\left(T_{t}-T_{a}\right) d z
$$

$T_{a}$ and $T_{t}$ are the temperatures in the annulus and the tube, ${ }^{\circ} \mathrm{C} ; C_{a}$ is the specific heat of the fluid, $\mathrm{J} / \mathrm{kg}^{\circ} \mathrm{C}$; 
The intermediate parameter

$$
B=\frac{w_{a} c_{a}}{2 \pi r_{t i} U_{t}}
$$

$U_{t}$ is the heat transfer coefficient of the annulus fluid and the drill $\operatorname{rod}, \mathrm{W} /\left(\mathrm{m}^{2 \circ} \mathrm{C}\right)$ (e.g. Jakob [6]):

$$
U_{t}=\left[\frac{1}{h_{t}}+\frac{r_{t i} \ln \left(r_{t 0} / r_{t i}\right)}{k_{t}}+\frac{r_{t i}}{r_{t o}} \frac{1}{h_{a}}\right]^{-1}
$$

$k_{t}$ is the coefficient of heat conductivity of the tube, $\mathrm{W} /\left(\mathrm{m}^{2 \circ} \mathrm{C}\right) ; r_{t i}$ and $r_{t o}$ are the inner radius and the outer radius of the tube, $\mathrm{m}$;

$h_{t}$ and $h_{a}$ are the convective heat transfer coefficients of the fluid in the tube and the annulus, $\mathrm{W} /\left(\mathrm{m}^{20} \mathrm{C}\right)$.

Additionally, because the flow is stable and the compressibility of the fluid can be ignored, the following equation can be obtained:

$$
\frac{d T_{a}}{d z}=\frac{1}{B}\left(T_{a}-T_{t}\right)
$$

The differential equation of the energy of the inner tube can be obtained in the same way:

$$
\frac{d T_{t}}{d z}=\frac{w_{a}}{w_{t} B}\left(T_{a}-T_{t}\right)
$$

$w_{t}$ is the mass flow of the fluid, $\mathrm{kg} / \mathrm{s}$;

The following equation can be obtained by solving the differential equation of the energy of the annulus and the inner tube simultaneously:

$$
\frac{d^{2} T_{a}}{d z^{2}}+\frac{1}{B}\left(\frac{w_{a}}{w_{t}}-1\right) \frac{d T_{a}}{d z}=0
$$

Boundary conditions: while $\mathrm{z}=0, \mathrm{~T}_{\mathrm{t}}=\mathrm{T}_{\mathrm{t} 1}$ and $\mathrm{T}_{\mathrm{a}}=\mathrm{T}_{\mathrm{a} 1}$; while $\mathrm{z}=\mathrm{L}, \mathrm{T}_{\mathrm{t}}=\mathrm{T}_{\mathrm{t} 2}$; the experimental result value of the overall heat transfer coefficient is obtained:

$$
U_{t}=w_{a} c_{p a} \ln \left(\frac{T_{t 2}-T_{a 1}+\left(T_{t 1}-T_{a 1}\right) /(1-W)}{W\left(T_{t 1}-T_{a 1}\right) /(1-W)}\right) /\left[(1-W) 2 \pi r_{t i} L\right]
$$

wherein $W=w_{a} / w_{t}=v_{a} A_{a} /\left(v_{t} A_{t}\right)$, then the expression of the experimental value of heat transfer coefficient in the tube:

$$
\frac{1}{h_{t}}=\frac{\left(1-u_{a} A_{a} /\left(u_{t} A_{t}\right)\right) 2 \pi \pi_{t i} L}{\rho_{l} A_{a} u_{a} c_{p a} \ln \left\{\frac{T_{t 2}-T_{a 1}+\left(T_{t 1}-T_{a 1}\right) /\left[1-u_{a} A_{a} /\left(u_{t} A_{t}\right)\right]}{u_{a} A_{a} /\left(u_{t} A_{t}\right) \cdot\left(T_{t 1}-T_{a 1}\right) /\left[1-u_{a} A_{a} /\left(u_{t} A_{t}\right)\right]}\right\}}-\frac{r_{t i}}{k_{t}} \ln \left(\frac{r_{t 0}}{r_{t i}}\right)-\frac{r_{t i}}{r_{t o}} \frac{1}{h_{a}}
$$

wherein $v_{t}$ is the speed of the fluid in the inner tube, $\mathrm{m} / \mathrm{s} ; A_{a}$ and $A_{t}$ are the areas of the annulus and the inner tube, $\mathrm{m}^{2}$. 


\section{Cryogenic cooling heat transfer laws in the wellbore}

Although the heat transfer calculation methods of the flow patterns are different, the expression for the calculation of the single-phase flow or its revised type is used for all the flow patterns. Thus the heat transfer of the single phase is the basis for the heat transfer calculation of each two-phase flow pattern. Currently, as for the research on the fluid heat transfer at low temperatures $\left(0-6^{\circ} \mathrm{C}\right)$ in deepwater, there is still no document reported. Additionally, the seawater belongs to Type III boundary condition that is more complicated than the fluid in the wellbore and it is unrealistic to deduce the heat transfer expression purely in theory. So in this paper, the heat transfer laws of the fluid in the wellbore that simulates the cryogenic deepwater circumstance are studied by experiment.

As the three processes of the convection heat transfer between the fluid in the annulus and the outer layer of the inner tube, the heat conduction of the tube wall and the convection heat transfer between fluid in the tube and the inner tube wall are included in the heat transfer and the three processes are interrelated, it cannot be directly solved. In this paper, the trial and error procedure are adopted to obtain the convection heat-transfer coefficient. Then the parameters in the equation are determined according to the criterion equation $N u=C \operatorname{Re}^{n} \operatorname{Pr}^{m}$. Wherein, $C, n$ and $m$ are the undetermined coefficient and index in line with their definitions. Set $\mathrm{CPr}^{\mathrm{m}}$ equal to $\mathrm{A}$ and take the logarithm of both sides of the equation above. Then equation (10) is obtained:

$$
\lg N u=\lg A+n \lg \operatorname{Re}
$$

Because the $N u$ and $R e$ in different flow patterns measured in the experiment are in a straight line on the coordinate axes of $\lg R e$ and $\operatorname{lgN} u$, thus $\mathrm{A}$ and $\mathrm{n}$ can be determined.

The experiment is carried out under the condition of cooling heat transfer. According to the conventional criterion relational expression of heat transfer, 1/3 is selected for the exponent of $P r$ in the laminar flow and the transition flow and 0.3 is selected in the turbulent flow because $P r$ is the function of the natural characteristic of the fluid and it is independent of the flow speed. Based on the experimental data, we obtain the relationship between $R e$ and $N u$, as shown in Fig. 4. On the whole $\operatorname{lgN} u$ and $\lg R e$ are linear. Especially they are entirely consistent with the criterion equation in the laminar flow and the turbulent flow. But the laws in the transition flow are very complicated. So many researchers suggest that the transition flow should be evaded for the research of heat transfer. In view of the actual engineering requirements, the above-mentioned criterion definition is still adopted because the scope of the transition flow is narrow and too complicated expression will be too difficult for the calculation. The relational expression of $\mathrm{Nu}$ in the tube is obtained through regression:

$$
\begin{gathered}
N u=0.001873 \operatorname{Re}^{1.02} \operatorname{Pr}^{1 / 3} \quad \operatorname{Re}<2000 \\
N u=0.10219 \operatorname{Re}^{0.6384} \operatorname{Pr}^{1 / 3} \quad 2000<\operatorname{Re}<10000 \\
N u=0.02694 \operatorname{Re}^{0.7922} \operatorname{Pr}^{0.3} \operatorname{Re}>10000
\end{gathered}
$$




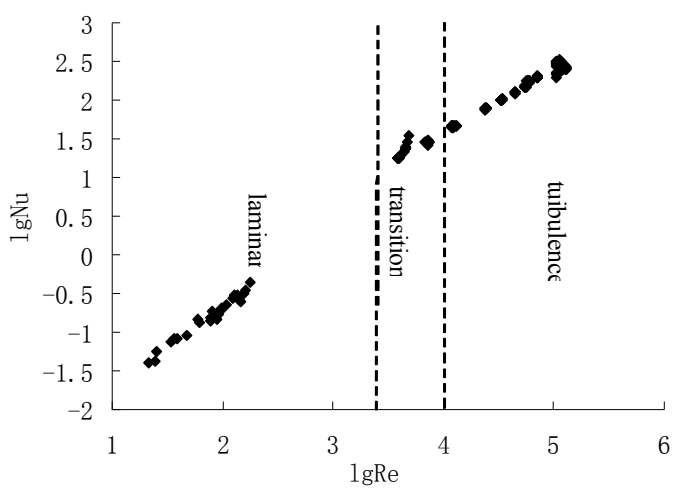

Figure 4: Relationship of $\mathrm{Nu}$ and $\mathrm{Re}$ in tuibulence flow.

According to the relational expression of the heat transfer in each flow pattern, the exponent of the Reynolds number decreases and the strength of the heat transfer increases from the laminar flow to the turbulent flow. That is because the temperature distribution of the turbulent flow core is flat except the adherent lower layer of the laminar flow, according to the heat transfer boundary layer theory. The main thermal resistance is in the lower layer of the laminar flow, which is extremely thin. So the temperature gradient is extremely great (e.g. Yang and Wenquan [7]). From the perspective of energy, the flow speed in the laminar flow is relatively low and thus the interaction among the particles of the fluid is very small. The flow becomes very disordered with vortex and fluctuation when it reaches the turbulent flow. Then the interaction among the particles of the fluid becomes strong. The internal energy increases because of the converted internal energy from partial kinetic energy. And then the change of the temperature gradient is more obvious and the heat transfer is more intense.

\section{Influence factors of cryogenic cooling heat transfer in each flow pattern}

\subsection{Bubbly flow}

The bubbly flow is the simplest and most basic flow pattern in the gas-liquid two-phase flow. Its characteristic is that the gas phase is distributed in the continuous liquid phase in the form of small discrete bubbles with the feature of stable and uniform flow. Because of limited experimental conditions, the gas discharge Qg has to be limited above $8 \mathrm{~m} 3 / \mathrm{hr}$ and the liquid discharge also must be within $11 \mathrm{~m}^{3} / \mathrm{hr}$. A series of experiments are carried out for the research on the influence of the liquid discharge on the convective heat-transfer coefficient in the tube $\left(\mathrm{h}, \mathrm{W} /\left(\mathrm{m} 2^{\circ} \mathrm{C}\right)\right)$ and the results are shown in Fig. 5.

The numerical relational expression of the heat transfer coefficient and the liquid discharge is obtained with the gas discharge of $8 \mathrm{~m}^{3} / \mathrm{hr}$ through regression:

$$
h=91.093 Q_{l}+740
$$




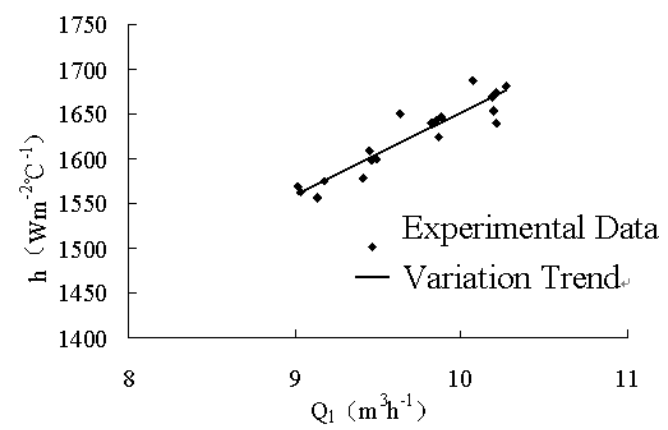

Figure 5: Influence of liquid discharge on heat transfer.

The results of the experiment show that the convective heat-transfer coefficient in the tube rises in a straight line along with the increase of the liquid discharge. That is because the liquid phase is the main part in this kind of pseudo-single-phase flow such as the bubbly flow and the proportion of the liquid in the annulus increases along with the liquid discharge. From the formula of the heat transfer $h=N u \lambda / d$, we can see that the heat transfer coefficient $h$, $N u$, and the coefficient of heat conductivity of the fluid $\lambda$ are related with the tube diameter $d$. However, in the bubbly flow, the liquid discharge is greater than the gas discharge. Then according to the expression of $N u$, the relevant parameters of the two phases of gas and liquid, and the much larger heat conductivity of the liquid phase than the gas phase, the conclusion is drawn that the heat transfer is mainly influenced by the liquid phase. The Reynolds number $R e$ and the heat transfer coefficient increases along with liquid phase discharge.

\subsection{Slug flow}

As the gas content rises, some big bubbles accumulated by some smaller bubbles appear in the center of the tube at intervals. The big bubble is called Taylor bubble. The differential pressure decreases obviously while a big Taylor bubble passes. The slug flow is also a kind of basic flow pattern. However, because of the obvious feature of subsections of the slug flow, both the void fraction distribution and the differential pressure distribution have large fluctuations. It has characteristic of great flow fluctuation and alternation of gas and liquid. a large amount of experiments are carried out for the research on the influence of the liquid discharge and the gas discharge on the convective heat-transfer coefficient. The experimental results are shown in Fig. 6 and Fig. 7. Through regression the numerical relational expressions of the heat transfer coefficient with the discharge are obtained when the liquid discharges are $14 \mathrm{~m}^{3} / \mathrm{h}, 15 \mathrm{~m}^{3} / \mathrm{h}$ and $30 \mathrm{~m}^{3} / \mathrm{h}$ and the gas discharges are $5.44 \mathrm{~m}^{3} / \mathrm{h}, 6.14 \mathrm{~m}^{3} / \mathrm{h}$ and $7.89 \mathrm{~m}^{3} / \mathrm{h}$. Wherein, the heat transfer coefficient is an average value in a long time period when the flow and the heat transfer are stable. 


$$
\begin{gathered}
h_{l 1}=2352.4 Q_{l 1}-5431.6, \\
h_{l 2}=2250.9 Q_{l 2}-5906.4, \\
h_{l 3}=1298.8 Q_{l 3}-3886.3 \\
h_{g 1}=2.0625 Q_{g 1}+1780.5 \\
h_{g 2}=11.961 Q_{g 2}+1681.6, \\
h_{g 3}=18.552 Q_{g 3}+1651.8
\end{gathered}
$$

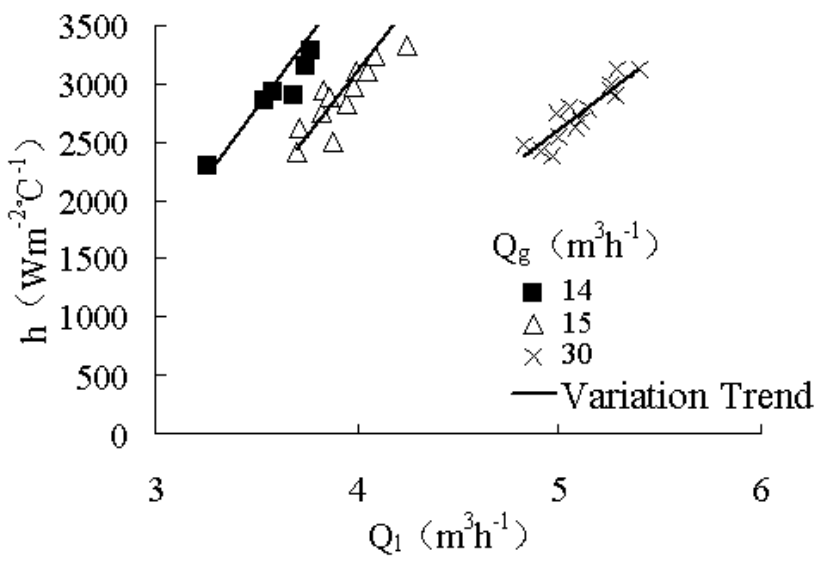

Figure 6: Influence of liquid discharge on heat transfer.

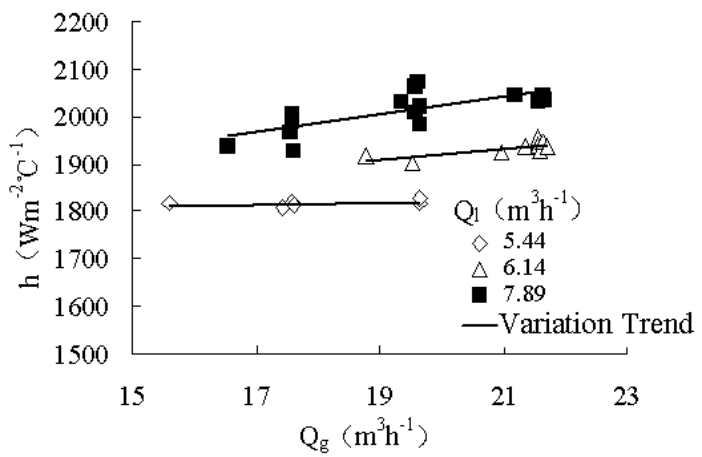

Figure 7: Influence of gas discharge on heat transfer. 
From the relational expression, it can be seen that both the heat transfer coefficient-liquid discharge and the heat transfer coefficient-gas discharge are linear. As the liquid discharge rises, the convective heat-transfer coefficient in the tube rises rapidly. However, the change of the convective heat-transfer coefficient is very small as the gas discharge rises. On the other hand, when the gas discharge is larger, the influence of the liquid discharge on the convective heat-transfer coefficient decreases. And when the liquid discharge is larger, the influence of the gas discharge on the convective heat-transfer coefficient increases. In the slug flow, the liquid discharge is still the main influence factor. That is because the heat transfer coefficient, $N u$, and the heat conductivity of the fluid are related with the tube diameter. In the slug flow, the liquid discharge and the gas discharge are still of the same order of magnitude and the difference is not very large. Then according to the expression of $N u$, the relevant parameters of the two phases of gas and liquid, and the much larger heat conductivity of the liquid phase than the gas phase, the conclusion is that the heat transfer is mainly influenced by the liquid phase. The Re number and the heat transfer coefficient increases along with liquid phase discharge.

\subsection{Churn flow}

If the void fraction is greater than the scope of the slug flow, the Taylor bubble bursts and the flow changes to churn flow. The appearance of big vortexes and bubbles cause violent jarring to the flow. The shape and size of the gas become irregular. The gas and liquid intrudes each other and they are highly decentralized in the area away from the wall. At this time, a highly disordered state emerges. It has the characteristic of a high degree of disorder and violent jarring. A large amount of experiments are carried out for the research on the influence of the liquid discharge and the gas discharge on the convective heattransfer coefficient of the churn flow. The experimental results are shown in Fig. 8 and Fig. 9. Through regression the numerical relational expression of the heat transfer coefficient and the liquid discharge and the gas discharge is obtained with the gas discharge of $46 \mathrm{~m}^{3} / \mathrm{hr}$ and the liquid discharge of $2.5 \mathrm{~m}^{3} / \mathrm{hr}$.

$$
\begin{gathered}
h=-8.7564 Q_{l}+2047 \\
h=0.2777 Q_{g}+2006.6
\end{gathered}
$$

From the relational expression, it can be seen that the change of the liquid discharge and the gas discharge has little influence on the heat transfer coefficient in the tube. That is because the gas constitutes the most part in the churn flow while what influences the heat transfer most is the liquid area near the wall. The core entrainment rate of the gas increases as the liquid discharge increases (e.g. Azzopardi and Wren [8]). Therefore, even if the change of the liquid discharge is great, its influence on the heat transfer coefficient is still small. In addition, during the research, the speed of the gas is basically over $5 \mathrm{~m} / \mathrm{s}$. So the entraining liquid discharge in the gas also does not change 
(e.g. Azzopardi and Wren [8]) according to the formula of the entrainment rate of the gas. So the liquid area near the wall is stable. Even if the gas discharge increases, the heat transfer coefficient is basically stable.

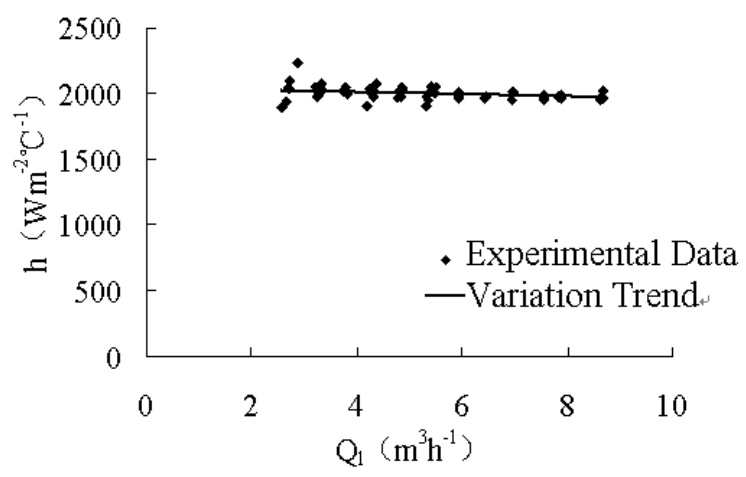

Figure 8: Influence of liquid discharge on heat transfer.

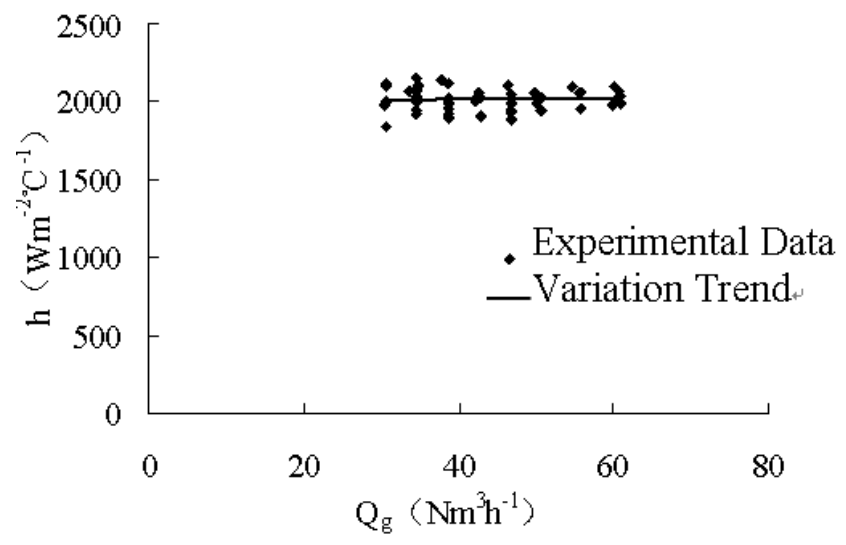

Figure 9: Influence of gas discharge on heat transfer.

\subsection{Annular flow}

When the void fraction reaches a certain value, the liquid proportion in the cross section reduces further. For the speed of the gas increases further, its entrainment function becomes more and more obvious. Then the liquid film forms in the area near the wall and the mist flow core formed by the entraining liquid in the gas forms in the center of the tube, which is called annular flow. In the annular flow, the mist flow core and the liquid film near the wall are in a relatively stable state because the amount of the liquid that the mist flow core can entrain is balanced. Then both the gas phase and the liquid phase near the wall are continuous phases. The liquid in the mist core is discontinuous phase. It has the characteristic of stable flow. A series of experiments are carried out for the 
research on the influence of the liquid discharge and the gas discharge on the convective heat-transfer coefficient in the tube. The experimental results are shown in Fig. 10 and Fig. 11.

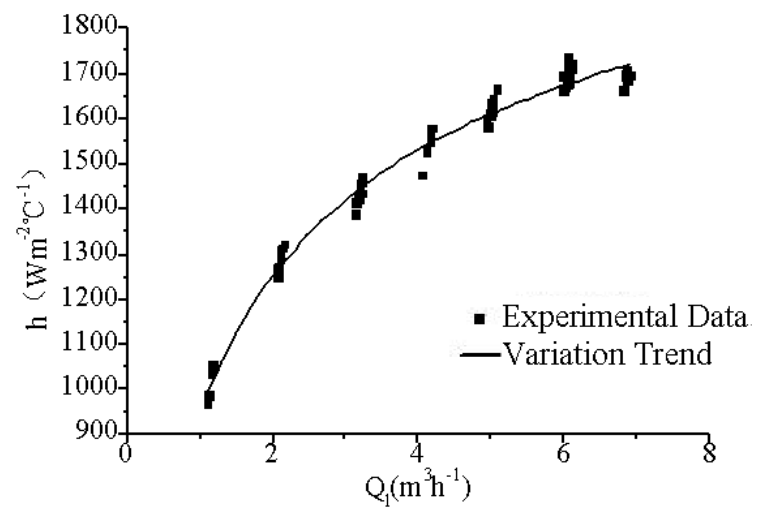

Figure 10: Influence of liquid discharge on heat transfer.

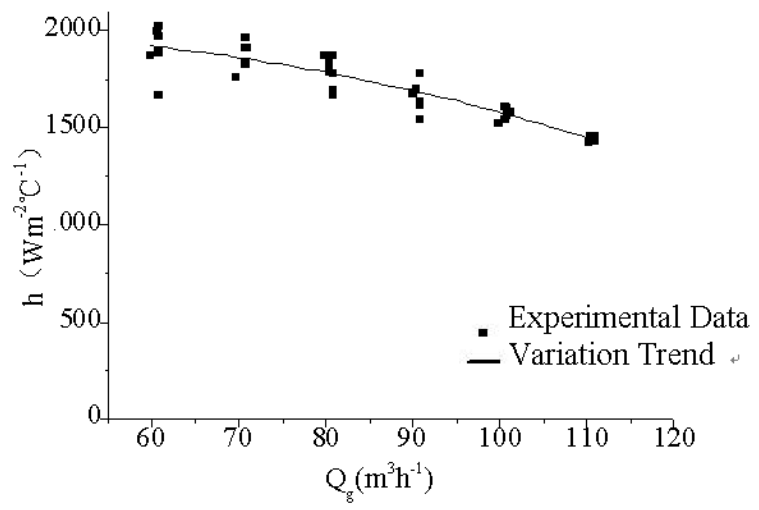

Figure 11: Influence of gas discharge on heat transfer.

The numerical relational expression of the heat transfer coefficient and the discharge is obtained with the gas discharge of $170 \mathrm{~m}^{3} / \mathrm{hr}$ and the liquid discharge of $0.707 \mathrm{~m}^{3} / \mathrm{hr}$ through regression:

$$
\begin{gathered}
h=2467.78347-\frac{3358.81169}{1+\left(\frac{Q_{l}}{0.7161}\right)^{0.55174}} \\
h=2044.77436-0.00285 Q_{g}^{2.6064}
\end{gathered}
$$


The convective heat-transfer coefficient increases with non-linearity as the liquid discharge while it decreases with non-linearity as the gas discharge. That is because the density and relevant thermal parameters of the gas and the liquid differ by two orders of magnitude, although the amount of the liquid is small, when the change of the liquid discharge is larger, it still has obvious influence on the heat transfer. On the other hand, what influences the convective heat transfer mostly in the annular flow is the liquid film area near the wall. The liquid entrainment rate of the mist flow core is only related with the apparent speed of the gas. If the gas discharge increases, the entrainment rate increases with nonlinearity. The discharge in the liquid film is bound to reduce when the entrainment amount increases. Then it brings about the reduction of the convective heat-transfer coefficient in the tube.

\subsection{Influence of average void fraction}

To understand the influence of the gas discharge and the liquid discharge on heat transfer more fully, the parameter average void fraction is selected in this paper. Its definition:

$$
\alpha_{s}=\frac{v_{s g}}{v_{s g}+v_{s l}}=\frac{Q_{g}}{Q_{g}+Q_{l}}
$$

The heat transfer experiments with different liquid discharge and gas discharge are carried out, as shown in Fig. 12.

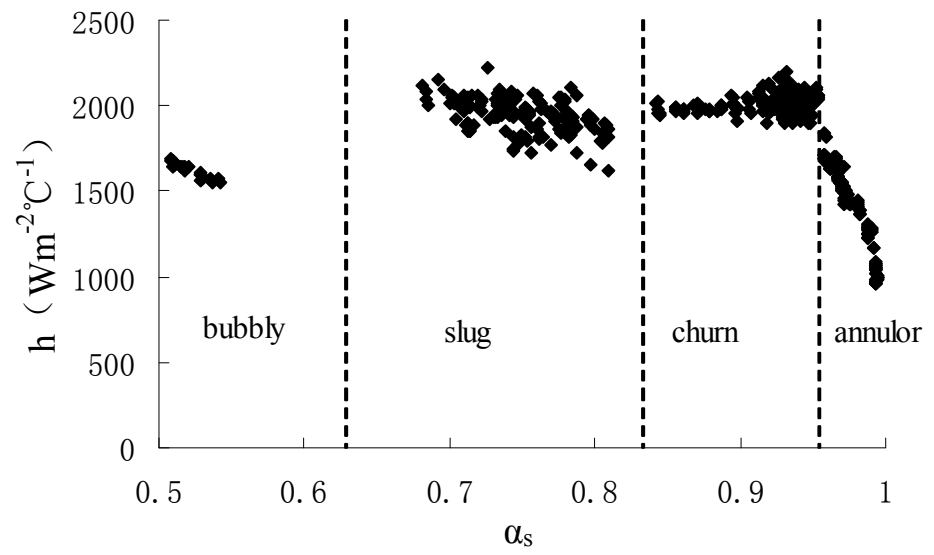

Figure 12: Influence of average void fraction on heat transfer.

On the whole, when the average void fraction increases, the heat transfer coefficient increases first and then decreases. However, the change trend of each specific flow pattern differs. The numerical expression of the heat transfer coefficient and the average void fraction is obtained under the experimental condition through regression: 


$$
\begin{aligned}
& h=3518.8-3637.6 \alpha_{s} \\
& h=-19716 \alpha_{s}+20682 \\
& h=-1419.3 \alpha_{s}+3013.9 \\
& h=442.93 \alpha_{s}+1604.8
\end{aligned}
$$

The convective heat-transfer coefficient in the tube decreases as the average void fraction increases in the scope of the bubbly flow and the slug flow. The convective heat-transfer coefficient changes little in the scope of the churn flow. The convective heat-transfer coefficient decreases rapidly in the scope of the annular flow. That is because the bubbly flow is similar to the single phase flow. The proportion of the gas in the section of the tube increases as the average void fraction increases. The difference of the $N u$ number of the gas and the liquid is not great in the bubbly flow and the heat conductivity of the liquid phase is much larger than the gas phase. So the heat transfer coefficient is bound to decrease as the proportion of the liquid phase. In the slug flow, the void fraction changes little in the section of Taylor bubbles when the average void fraction increases. However, in the liquid slug section, the proportion of the gas in the section of the tube increases when the average void fraction increases and the thermal property of the air is much worse than the water. So for the two reasons the overall heat transfer coefficient decreases. In the churn flow and the annular flow, the changes of the heat transfer coefficients under the two conditions have been expounded above.

\section{Conclusion}

(1) In the paper, several heat transfer experiments are designed with the consideration of the heat transfer characteristics of each flow pattern and the characteristics of the cooling heat transfer based on the current research. The experimental system and the data processing methods are introduced in the paper.

(2) The relational expression for the calculation of the heat transfer in the turbulent flow under the deepwater cryogenic condition is basically consistent with that at normal temperature. However, the difference of the relational expression in the laminar flow is great.

(3) The liquid phase discharge is the main factor that influences the heat transfer in the bubbly flow, slug flow and the annular flow.

(4) The changes of the liquid discharge and the gas discharge have little influence on the heat transfer in the churn flow. Although the amount of the entraining liquid in the mist flow core will increase relatively when the liquid discharge increases, the mist flow core has little influence on the heat transfer. The net upwardly change of the liquid near the wall is the most important factor on the heat transfer in the churn flow. 


\section{Acknowledgements}

This work is supported by the Major Program of National Natural Science Foundation of China (No.51034007), the National Science and Technology Major Project of China (No.2011ZX05026-001-02), the National Natural Science Foundation of China (No.50874116, No.51104172 and No.51004113), the Natural Science Foundation of Shandong Provence of China (No.ZR2010EL101 and No.ZR2009FQ005) and the Fundamental Research Funds for the Central Universities, China.

\section{References}

[1] Taitel Y, Barnea D, Two phase slug flow. Adv Heat Transfer, 20, pp. 3132, 1990.

[2] Zheng zheng quan, Transient Simulation and Experiment Investigation of Cryogenic Two Phase Flow. Cryogenics and Superconductivity, 27(4), pp. 21-26, 1999.

[3] Liu Jinghua, Temperature Measurement in Void Test of Low Temperature Two-Phase Flow. Cryogenics, 86, pp. 12-14, 1995.

[4] Fan Shangchun, Zhou Haomin, Signal and Measurement Technology. Beijing: Press of Beijing University of Aeronautics and Astronautics, 2003.

[5] Gao Yonghai, Sun Baojiang, Wang Zhiyuan, Calculation and Analysis of Wellbore Temperature Field in Deepwater Drilling. Journal of the University of Petroleum, China (Edition of Natural Science).

[6] Jakob M, Heat transfer. New York: John Wiley and Sons Inc, 2, pp. 211260, 1957.

[7] Yang Shiming, Tao Wenquan, Heat Transfe. Beijing: Higher Education Press, pp. 104-108, 1998.

[8] B.J.Azzopardi, E.Wren, What is Entrainment in Vertical Two-phase Churn Flow. International Jounal of Multiphase Flow, 30, pp. 89-103, 2004.

[9] A.R.Hasan, C.S.Kabir, A Simple Model for Annular Two-Phase Flow in Wellbores. SPE Annual Technical Conference and Exhibition, Dallas, pp. 9-12, 2005.

[10] Zhang Zixion, Dong Zengnan, Viscous Fluid Flow. Beijing: Tsinghua University Press, pp. 351-387, 1998. 